Arq. Bras. Med. Vet. Zootec., v.65, n.3, p.757-762, 2013

\title{
Cimento de aluminato de cálcio: uso em defeitos ósseos induzidos em fêmur de coelhos
}

[Calcium aluminate cement: used in bone defects induced in the femur of rabbits]

\author{
C.P. Burger ${ }^{1}$, P.C. Moraes $^{1}$, C.L. Maniscalco ${ }^{1}$, P.A. Borges ${ }^{1}$, P.A.C.S. Batista ${ }^{1}$, J.C. Canola ${ }^{1}$, \\ A.E.W.B. Meirelles ${ }^{1}$, M.G. Sabino ${ }^{2}$, H. Rossetto ${ }^{2}$ \\ ${ }^{1}$ Faculdade de Ciências Agrárias e Veterinárias - Universidade Estadual Paulista (UNESP) - Campus Jaboticabal, SP \\ ${ }^{2}$ Binderware Biomateriais Ltda. - São Carlos, SP
}

\section{RESUMO}

Avaliou-se o comportamento do cimento de aluminato de cálcio em defeitos ósseos induzidos experimentalmente em fêmur de 12 coelhos Nova Zelândia Branco, distribuídos em três grupos experimentais, correspondentes aos tempos de observação pós-operatória de 15 (G15), 30 (G30) e 60 (G60) dias. Realizaram-se avaliações clínico-cirúrgicas, radiográficas e histológicas, a fim de se observar o potencial osteoindutor e osteocondutor do biomaterial no defeito ósseo, e se houve osteointegração. O cimento de aluminato de cálcio, na formulação utilizada, mostrou-se biocompatível, porém não atuou como osteocondutor ou osteoindutor.

Palavras-chave: coelho, biomaterial, consolidação óssea

\begin{abstract}
The patterns of the calcium aluminate cement in bone defects experimentally induced in the femur of 12 New Zealand White rabbits were evaluated. The animals were distributed in three experimental groups, corresponding to postoperative observation periods of 15 (G15), 30 (G30) and 60 (G60) days. Clinical, surgical, radiographic and histological appraisals were made to observe the osteoinductor and osteoconductor potential of the biological material, as well as the bone integration. The calcium aluminate cement formulation was biocompatible, but has not acted as a osteoconductor or osteoinductor.
\end{abstract}

Keywords: rabbit, biomaterial, bone healing

\section{INTRODUÇÃO}

$\mathrm{Na}$ cirurgia ortopédica, ocorrem com frequência situações de alteração na continuidade óssea, especialmente nos traumatismos de alta energia, tumores ou infecções (Ignácio et al., 2002). Embora a consolidação óssea seja um processo biológico aperfeiçoado, estima-se que 5 a $10 \%$ das fraturas em seres humanos apresentem complicações (Einhorn, 1995). Em animais, sabe-se que a incidência destas é dependente de fatores intrínsecos e extrínsecos, mas ainda não existem dados que expressem estatisticamente a sua ocorrência (Mayr et al., 2000).
A literatura relacionada à ortopedia cita diversos métodos alternativos de estimulação do reparo ósseo. Eles foram desenvolvidos objetivando acelerar o processo de consolidação de fraturas recentes e tratamento de problemas de união óssea e pseudoartrose (Mayr et al., 2000), além de reduzir o tempo de recuperação, garantindo retorno precoce da função do membro, e também diminuir seu custo (Croci et al., 2003; Moraes, 2006). Na medicina veterinária, essas necessidades tornam-se maiores pela dificuldade de se conseguir repouso adequado dos pacientes e, dessa forma, impedir a sobrecarga precoce ao osso fraturado (Moraes, 2006).

Recebido em 11 de outubro de 2011

Aceito em 11 de outubro de 2012

E-mail: ca_birg@hotmail.com 
Nesse contexto, pesquisas relacionadas à bioengenharia vêm crescendo significativamente, na busca de materiais que facilitem a regeneração óssea em fraturas ou em casos de falhas ósseas decorrentes de não-uniões e neoplasias. Apesar do grande número de estudos, ainda não foi descrito um produto ideal para uso isolado (Santos, 2000; Moraes, 2002; Anrizeh et al., 2003; Moraes et al., 2004; Oriá, 2005). Em geral, os biomateriais não devem ter resposta do tecido hospedeiro e, para tanto, devem assemelhar-se quimicamente ao mesmo. Com isso ocorre a biocompatibilidade, ou seja, não induz a resposta tecidual ou imunológica adversa. Além disso, a biofuncionalidade só se manifesta se a biocompatibilidade for adequada (Campos et al., 2005).

Assim, surgiram as pesquisas para adaptação de uma formulação cimentícia à base de aluminato de cálcio capaz de ser utilizada como biomaterial. Iniciaram-se na Universidade Federal de São Carlos, que posteriormente transferiu a tecnologia para a empresa Binderware Biomateriais Ltda., uma spin-off cujo objetivo é inovar para ter competitividade. A formulação, a princípio, fora voltada para aplicação na odontologia, mais especificamente na endodontia, tendo alcançado desempenho suficiente para se transformar em alternativa para o agregado de trióxidos minerais (MTA), o cimento endodôntico mais usado na atualidade.

Dessa forma, objetivou-se com este trabalho avaliar o comportamento do cimento de aluminato de cálcio em defeitos ósseos induzidos experimentalmente em fêmur de coelhos.

\section{MATERIAL E MÉTODOS}

Utilizaram-se 12 animais da espécie leporina (Oryctolagus cuniculus; Lilljeborg, 1874), raça Nova Zelândia Branco, adultos jovens, machos, não castrados, com peso corpóreo médio de $3,5 \mathrm{~kg}$. Os animais foram mantidos em gaiolas individuais, com ração própria para a espécie e água ad libitum, e foram distribuídos aleatoriamente em três grupos experimentais com quatro animais cada, correspondentes aos tempos de observação do pós-operatório de 15 (G15), 30 (G30) e 60 (G60) dias.

O projeto de pesquisa foi aprovado pela Comissão de Ética e Bem-Estar Animal da
Faculdade de Ciências Agrárias e Veterinárias da UNESP, Campus de Jaboticabal, sob o protocolo $\mathrm{n}^{\circ}$ 006693-09, de acordo com os Princípios Éticos de Experimentação Animal, adotado pelo Colégio de Experimentação Animal. Também seguiu as Normas da American Society for Testing and Materials, de acordo com o Standard Practice for Assessment of Compatibility of Biomaterials for Surgical Implants with Respect to Effect of Materials on Muscle and Bone (2004).

Submeteram-se os animais à anestesia inalatória com isofluorano, e prosseguiu-se com duas perfurações no terço médio da diáfise dos fêmures direito e esquerdo com diâmetro $3,5 \mathrm{~mm}$ e profundidade até a segunda cortical (Fig. 1). No fêmur direito os orifícios foram preenchidos com o cimento aluminoso, e os do lado esquerdo, apenas com coágulo sanguíneo. Ao término do procedimento cirúrgico, iniciouse antibioticoterapia com enrofloxacina e analgesia com cloridrato de tramadol e, até a remoção dos pontos, curativo tópico diário com iodo povidine. Foram feitas avaliações clínica, radiográfica, de acordo com o sistema de classificação modificada de Rezende et al. (1998), e histológica.

\section{RESULTADOS E DISCUSSÃO}

$\mathrm{Na}$ prática ortopédica, frequentemente $\mathrm{o}$ cirurgião se depara com perda substancial de tecido ósseo, de diversas causas, sendo necessária a aplicação de enxertos ou implantes. Ossos, metais e polímeros são os materiais mais comumente empregados, entretanto nenhum deles se destaca como o ideal, além das limitações impostas na sua utilização (Moraes, 2002). É sabido que a melhor escolha recai sobre o tecido ósseo autógeno, pois possui células vivas que estimulam a osteogênese. No entanto, suas desvantagens incluem o aumento do tempo operatório, dificuldade de conformação exata ao defeito e quantidade insuficiente de osso para a restauração (Constantino et al., 1991; Munting et al., 1993; Kurashina et al., 1998; Weinfeld, 1999).

O estudo do aluminato de cálcio tem o intuito de usá-lo na rotina da cirurgia ortopédica, visto que sua biocompatibilidade já fora comprovada em testes realizados na odontologia (Pandolfelli et al., 2008). A principal vantagem desse 
biomaterial é o menor tempo de endurecimento, aliado à maior resistência mecânica, quando comparado com outros materiais já destinados para esse fim (Pandolfelli et al., 2008; Jacobovitz et al., 2009).

Os animais, durante o período de avaliação pósoperatória, não apresentaram nenhuma reação tecidual adversa. Tiveram excelente regeneração da ferida cirúrgica e ausência de complicações, como claudicação, corroborando Moraes (2002).

As radiografias sequenciais aos zero, 15, 30 e 60 dias do fêmur controle de todos os animais revelaram aumento da radiopacidade diretamente proporcional ao tempo de avaliação da reparação óssea. Aos 60 dias, foi possível identificar, radiograficamente, apenas a silhueta do defeito. Esse fato corrobora os achados de outros autores, com diversos materiais em sítios ósseos diferentes (Borges, 1998; Rezende et al., 1998; Fehlberg, 2001; Vital et al., 2006; Moraes et al., 2007).

Nos defeitos preenchidos com o cimento de aluminato, foi visibilizada radiopacidade maior do que a do osso normal, que permaneceu inalterada durante todo o período de avaliação pós-operatória. É importante ressaltar que, mesmo com maior lentidão, houve reparação da superfície periostal do defeito, sugerindo que a presença do biomaterial estivesse impedindo a circulação de células no local. Estes resultados confrontaram os de Rezende et al. (1998), Vital et al. (2006) e Freitas et al. (2008), que encontraram redução gradativa da radiopacidade nos materiais por eles testados.

À histologia, aos 15 dias de observação nos orifícios controle, foi evidenciada formação de tecido ósseo primário, gradualmente substituído por secundário ou maduro aos 30 e 60 dias, sendo neste último totalmente preenchido. Estes resultados divergem dos encontrados por Ignácio et al. (2002), em seu grupo controle, com formação de tecido conjuntivo fibroso em seu interior, sem neoformação óssea, mesmo aos 12 meses de observação. Resultados semelhantes foram verificados por Santos Neto (1982) e, posteriormente, por Ignácio et al. (1997), que também não obtiveram consolidação de falhas ósseas extensas produzidas em cães e coelhos, respectivamente, quando deixadas vazias. Entretanto, assemelham-se aos resultados descritos na literatura por vários autores que trabalharam com defeitos não críticos, como os do presente trabalho (Borges, 1998; Franco, 2000; Fehlberg, 2001; Prado et al., 2006; Vital et al., 2006). Com base nesses achados divergentes, nota-se que a reparação óssea acontece de forma natural, dependendo do tamanho do defeito.

Nos defeitos tratados não foi encontrada formação óssea no interior do cimento aluminoso, nos 15 e 30 dias de pós-operatório, e somente aos 60 dias foi possível identificar uma discreta invasão de tecido ósseo. Esse retardo, se comparado aos orifícios vazios, pode ser explicado pela reduzida porosidade e pela dimensão dos poros característicos do material. Moraes et al. (2004) obtiveram resultados semelhantes quando da utilização do cimento de fosfato de cálcio e relacionaram os achados com o menor tempo de endurecimento e maior resistência mecânica (Fig. 1).

A presença do infiltrado inflamatório durante mais tempo ao redor dos defeitos preenchidos com o cimento de aluminato de cálcio pode ser explicada pela tentativa de reparo do hospedeiro, visto que a inflamação é uma das etapas da consolidação óssea (Phillips, 2005; Sojo et al., 2005). Ademais, a já citada baixa porosidade também pode ter dificultado esse processo.

Dependendo do objetivo para a utilização desse tipo de material, a porosidade é relevante. Para que a resistência seja alta, os poros devem ser poucos e de tamanho reduzido. Dessa forma, a infiltração do material por células do hospedeiro fica prejudicada, quando não impedida. Por outro lado, tais propriedades garantem uma barreira contra a microinfiltração bacteriana, em adição à alcalinidade que torna o meio inóspito ao crescimento de colônias na superfície do material. Portanto, para a odontologia, esses atributos são importantes, pois promovem o selamento das cavidades endodônticas (Jacobovitz et al., 2009). Já na ortopedia, é indispensável que haja penetração celular no implante, para que este possa ser considerado biomaterial osteocondutor ou, ainda, osteoindutor, havendo a osteointegração. Assim, provavelmente, os resultados poderiam ter sido diferentes caso a porosidade fosse maior, mesmo prejudicando a resistência mecânica. 


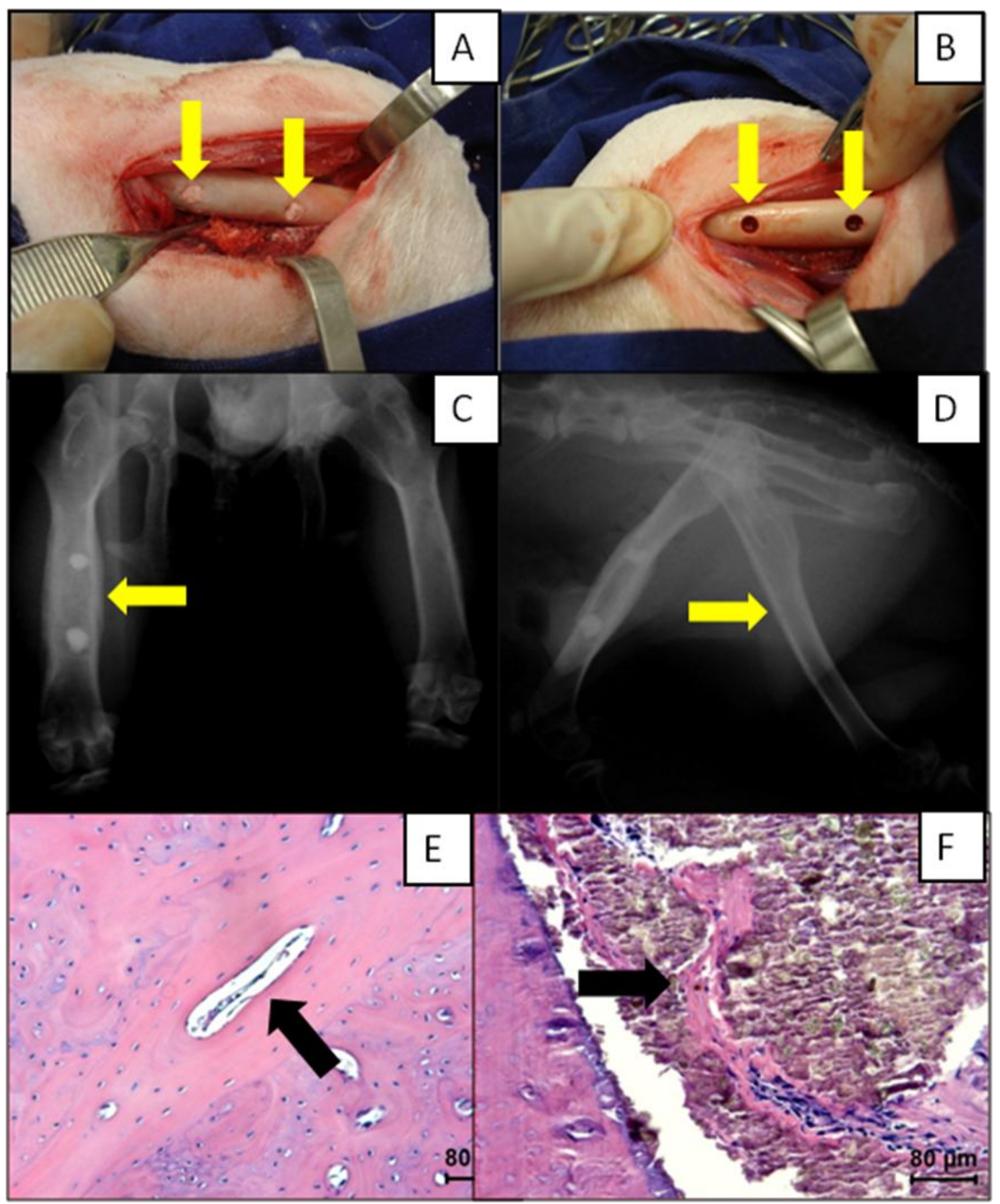

Figura 1. Coelho. Imagem fotográfica. A: fêmur direito com os orifícios preenchidos com o cimento aluminoso (setas): B: fêmur esquerdo com as perfurações preenchidas com coágulo (setas). Imagem radiográfica onde C e D: G60, com calo exuberante ao redor do cimento aluminoso (seta) e fechamento quase completo dos orifícios preenchidos por coágulo (seta). Fotomicrografia dos cortes histológicos onde E: tecido ósseo secundário com a presença de sistema de Harvers (seta); F: invasão de células ósseas (seta) na periferia do cimento aluminoso (Ci) Hematoxilina-Eosina; E e F20X). 


\section{CONCLUSÕES}

A reduzida porosidade do material impôs uma barreira física, que limitou a proliferação de vasos sanguíneos essenciais para o processo de reparação. O cimento de aluminato de cálcio, na formulação utilizada, mostrou-se biocompatível, porém não atuou como osteocondutor ou osteoindutor. Maior tempo de observação assim como a reformulação do cimento tornam-se necessários para melhor avaliar o comportamento do biomaterial nos defeitos ósseos induzidos em fêmur de coelhos.

\section{AGRADECIMENTOS}

Os autores agradecem ao Conselho Nacional de Desenvolvimento Científico e Tecnológico (CNPq) pela bolsa concedida; à Binderware Biomateriais Ltda., por conceder o biomaterial e auxílio financeiro para a realização desta pesquisa; e ao Prof. Paulo Tambasco de Oliveira, pela grande ajuda na avaliação histopatológica, além de todos que colaboraram para o ótimo andamento do projeto.

\section{REFERÊNCIAS}

ANRIZEH, T.L.; PETER, S.J.; ARCHAMBAULT, M.P. et al. Allogeneic mesenchymal stem cells regenerate bone in a critical size canine segmental defect. J. Bone Joint Surg. Am., v.85A, p.1927-1935, 2003.

BORGES, A.P.B. O efeito da hidroxiapatita sintética na regeneração óssea de defeito provocado experimentalmente no terço proximal da tíbia de cães: estudo clínico-cirúrgico, radiológico e histológico por microscopia de luz e microscopia eletrônica de retrodisperção. 1998. 112f. Tese (Doutorado) - Escola de Veterinária, Universidade Federal de Minas Gerais, Belo Horizonte.

CAMPOS, S.D.; CAMPOS, É.A.; SILVEIRA, C.B. et al. Biomateriais à base de $\mathrm{Na} 2 \mathrm{O}-\mathrm{CaO}-$ $\mathrm{SiO} 2-\mathrm{P} 2 \mathrm{O} 5$ preparados com serragem e com glucose de milho: influência na porosidade e na cristalinidade. Cerâmica, v.51, p.274-279, 2005.

CONSTANTINO, P.D.; FRIEDMAN， C.D.; JONES, K. et al. Hydroxyapatite cement, basic chemistry and histologic properties. Arch. Otolaryngol. Head Neck Surg., v.117, p.379-384, 1991.
CROCI, A.T.; CAMARGO, O.P.; BITAR, G. et al. Efeito do concentrado de plasma em falhas ósseas provocadas em fêmures de camundongos como estimulação de formação óssea - estudo experimental. Acta Ortop. Bras., v.11, p.230239, 2003.

EINHORN, T.A. Enhancement of fracturehealing. J. Bone Joint Surg., v.77, p.940-956, 1995.

FEHLBERG, A.F. Hidroxiapatita sintética na regeneração de falha óssea provocada em fratura completa de terço intermédio de tíbia imobilizada pela fixação percutânea em cães. 2001. 42 f. Tese (Mestrado) - Universidade Federal de Viçosa, Viçosa.

FRANCO, K.L. Avaliação clínico-cirúrgica, radiológica e histológica da reparação óssea após a utilização de HAP-91, COL.HAP-91 e INT.HAP-91 em defeito provocado experimentalmente na tíbia de cães. 2000. 22f. Monografia (Especialização) Universidade Federal de Viçosa, Viçosa, MG.

FREITAS, S.H.; DÓRIA, R.G.S.; MENDONÇA, F.S. et al. Aspecto radiológico de heteroenxerto ósseo cortical fragmentado na reparação de falhas ósseas em coelhos. Rev. Bras. Cien. Vet., v.15, p.107-110, 2008.

IGNÁCIO, H.; MAZZER, N.; BARBIERI, C.H. et al. Uso da poliuretana derivada do óleo de mamona para preencher defeitos ósseos diafisários segmentares do rádio: estudo experimental em coelhos. Rev. Bras. Ortop., v.3, p.815-821, 1997.

IGNÁCIO, H.; MAZZER, N.; BARBIERI, C.H. et al. Avaliação da poliuretana da mamona nas formas compacta e porosa no preenchimento de falha óssea: estudo experimental em cães. Rev. Bras. Ortop., v.37, p.187-194, 2002.

JACOBOVITZ, M.; VIANNA, M.E.; PANDOLFELLI, V.C. et al. Root Canal Filling with Cements Based on Mineral Aggregates: an in vitro Analysis of Bacterial Microleakage. Oral Surg. Oral Med. Oral Pathol. Oral Radiol. Endod., v.108, p.140-144, 2009 
KURASHINA, K.; KUTITA, H.; KOTANI, A. et al. Experimental cranioplsty and skeletal augmentation using an $\alpha$-tricalcium phosphate/ dicalcium phosphate dibasic/tetracalcium phosphate monoxide cement: a preliminary short-term experiment in rabbits. Biomaterials, v.19, p.701-706, 1998.

MAYR, E.; FRANKEL, V.; RUTER, A. Ultrasound - na alternative healing method for nonunions? Arch. Orthop. Trauma Surg., v.120, p.1-8, 2000.

MORAES, P.C. Biocompatibilidade $e$ comportamento do cimento de fosfato de cálcio, reforçado com diferentes tipos de fibras, implantado no rádio de coelhos. 2002, 73f. Dissertação (Mestrado em Cirurgia Veterinária) - Faculdade de Ciências Agrárias e Veterinárias, Universidade Estadual Paulista, Jaboticabal, SP.

MORAES, P.C. O uso do ultra-som pulsado de baixa intensidade em falhas ósseas produzidas experimentalmente em coelhos, preenchidas ou não com cimento de fosfato de cálcio. 2006. 44f. Tese (Doutorado em Cirurgia Veterinária) Faculdade de Ciências Agrárias e Veterinárias, Universidade Estadual Paulista, Jaboticabal, S.P.

MORAES, P.C.; PADILHA FILHO, J.G.; CANOLA, J.C. et al. Biocompatibilidade do cimento de fosfato de cálcio implantado em rádio de coelhos. Acta Cir. Bras., v.19, p.351-359, 2004.

MORAES, P.C.; PADILHA FILHO, J.G.; CANOLA, J.C. et al. Uso do ultra-som de baixa intensidade em falhas ósseas produzidas experimentalmente em rádios de coelhos, preenchidas ou não com cimento de fosfato de cálcio. Vet. Not., v.13, p.67-74, 2007.

MUNTING, E.; MIRTCHI, A.; LEMAITRE, J. Bone repair of defects filled with a phosphocalcic hydraulic cement: an In Vivo Study. J. Mater. Sci. Mater. Med., v.4, p.337344, 1993.

ORIÁ, A.P. Cimento de a-fosfato tricálcico de dupla pega e polimetilmetacrilato como implantes intra-oculares em coelhos (Oryctolagus cuniculus, Lilljeborg, 1874). 2005. 44f. Tese (Doutorado em Cirurgia Veterinária) Faculdade de Ciências Agrárias e Veterinárias, Universidade Estadual Paulista, Jaboticabal, S.P.
PANDOLFELLI, V.C.; OLIVEIRA, I.R.; JACOBOVITZ, M. et al. Composição à Base de Cimento Aluminoso para Aplicação em Endodontia e Produto Cimentício Obtido, INPIPI 0704502-6 (26/11/2007) e PCT-WO (26/11/2008).

PHILLIPS, A.M. Overview of the fracture healing cascade. Inj. Inter. J. Care Inj., v.36S, p.S5-S7, 2005.

PRADO, F.A.; ANBINDER, A.L.; JAIME, A.P.G. et al. Defeitos ósseos em tíbias de ratos: padronização do modelo experimental. Rev. Odontol. Univ. São Paulo, v.18, p.7-13, 2006.

REZENDE, C.M.F; BORGES, A.P.B.; BERNIS,W.O. et al. Aspecto clínico-cirúrgico e radiográficos da hidroxiapatita sintética na diáfise proximal da tíbia de cães. Arq. Bras. Med. Vet. Zootec., v.50, p.537-545, 1998.

SANTOS, L.A.; OLIVEIRA, L.C.; SILVA RIGO, E.C. et al. Fiber reinforced calcium phosphate cement. Artif. Organs, v.24, p.212216, 2000.

SANTOS NETO, F.L. Pseudartrose experimentalmente provocada em rádios de cães. Estudo do seu desenvolvimento. 1982. 74f. Dissertação (Mestrado) - Faculdade de Medicina de Ribeirão Preto, Universidade de São Paulo, Ribeirão Preto, SP.

SOJO, K.; SAWAKI, Y.; HATTORI, H. et al. Immunohistochemical study of vascular endotelial growth factor (VEGF) and bone morphogenetic protein-2, -4 (BMP-2,-4) on lengthened rat femurs. J. Cran-Maxil. Surg., v.33, p.238-452, 2005.

VITAL, C.C; BORGES, A.P.B.; FONSECA, C.C. et al. Biocompatibilidade e comportamento de compósitos de hidroxiapatita em falha óssea na ulna de coelhos. Arq. Bras. Med. Vet. Zootec., v.58, p.175-183, 2006.

WEINFELD, I.; MAGALHÃES, L.V.; VILA, N. Estudo histológico de um novo material (biobone) indicado para reparação óssea. Rev. Paul. Odontol., v.21, p.9-10, 1999. 